\title{
MEDIOS DE COMUNICACIÓN E IDENTIDAD A'UWẼ XAVANTE: MITO, RITUAL Y POLÍTICA EN EL BRASIL CENTRAL
}

\section{Media and A'uwẽ Xavante Identity: Myth, Ritual and Politics in Central Brasil}

\section{Meios de comunicação e identidade A'uwẽ Xavante: mito, ritual e política no Brasil central}

\author{
Rafael Franco Coelho, Universidad Federal de Goiás (UFG), Brasil \\ coelho.rafa@gmail.com
}

Amparo Huertas Bailén, Universitat Autònoma de Barcelona, España

amparo.huertas@uab.cat

\section{Recibido: 15 de mayo de 2017}

Aprobado: 28 de enero de 2018

\section{RESUMEN}

En este artículo, presentamos parte de los resultados de una investigación doctoral. La tesis fue el estudio de caso de Aldea Digital, un proyecto de educación mediática e inclusión digital con talleres de formación y capacitación del pueblo A'uwẽ Xavante para la producción de sus propios medios de comunicación. La investigación utilizó múltiples métodos, como entrevistas, grupos focales, investigación-acción, observación participante y etnografía, con destaque del uso de la fotografía y del audiovisual como técnicas de observación en el campo. En el texto, reflexionamos sobre la participación, influencia e impacto de los medios audiovisuales en la construcción de la identidad $A^{\prime}$ uwẽ Xavante y sus múltiples procesos de identificación: personal, social, político y cultural. Analizamos cómo los A'uwẽ Xavante se representan en los medios audiovisuales y la mediatización entre los A'uwẽ Xavante y los 'otros'. Además, demostramos 
cómo las formas tradicionales de autorrepresentación quedan reflejadas en los contenidos mediáticos que crean. Los resultados de la investigación muestran que las transformaciones de la identidad A'uwẽ Xavante en los medios tienen como principio básico la mitología A’uwẽ Xavante y su noción de persona basada en el cambio.

Palabras clave: medios de comunicación indígenas, identidad indígena, cine indígena, tierras bajas suramericanas, Xavante.

\section{ABSTRACT}

In this article, we present part of the results of a doctoral thesis. The thesis was the case study of Digital Village, a project of media education and digital inclusion with training workshops of the A'uwẽ Xavante people for the production of their own media. The research used multiple methods such as interviews, focus groups, action research, participant observation and ethnography, highlighting the use of photography and audiovisual material as methods of observation in the fieldwork. In the text, we reflect about the participation, influence and impact of the audiovisual media in the construction of A'uwẽ Xavante identity and their multiple identification processes: the personal, social, political and cultural processes. We analyze how the A'uwẽ Xavante self-represent themselves in the audiovisual media and the mediatization between the A'uwẽ Xavante and the 'others'. In addition, we demonstrate how the traditional forms of self-representation are reflected in the media contents that they create. The results of the investigation show that the transformations of A'uwẽ Xavante identity in the media have as a basic principle the A'uwẽ Xavante mythology and its notion of person based on change.

Keywords: Indigenous media, indigenous identity, indigenous cinema, lowland South America, Xavante.

\section{RESUMO}

Neste artigo, apresento parte dos resultados da minha tese doutoral. A tese foi o estudo de caso de Aldeia Digital, um projeto de educação mediática e inclusão digital com workshops de formação e capacitação do povo A'uwẽ Xavante para a produção dos seus próprios meios de comunicação. A pesquisa utilizou múltiplos métodos como entrevistas, grupos focais, a investigação-ação, a observação participante e a etnografia, com destaque ao uso da fotografia e do audiovisual como métodos de observação no campo. No texto, reflexiono sobre a participação, influência e impacto dos meios audiovisuais na construção da identidade A'uwẽ Xavante e os seus múltiplos processos de identificação: pessoal, social, político e cultural. Analiso como os A'uwẽ Xavante se representam nos meios audiovisuais e a mediatização entre os A'uwẽ Xavante e os 'outros'. Além disso, demonstro como as formas tradicionais de autorrepresentação ficam refletidas nos conteúdos mediáticos que criam. Os resultados da pes- 
quisa demonstram que as transformações da identidade A'uwẽ Xavante nos meios têm como princípio básico a mitologia A'uwẽ Xavante e a sua noção de pessoa baseada na mudança.

Palavras-chave: meios de comunicação indígenas, identidade indígena, cinema indígena, Xavante.

\section{Breve introducción de los A’uwẽ Xavante}

Según fuentes históricas, los A'uwẽ Xavante habitan el altiplano central de Brasil desde el siglo xvill, una región de la Amazonia legal, a donde llegaron migrando desde el norte del Estado de Goiás, entre los ríos Tocantins y Araguaia, hasta establecerse en el Estado de Mato Grosso.

Xavante es el nombre en portugués por el cual los brasileños identifican este grupo indígena. Pero ellos se identifican y autodenominan en su lengua como A'uwẽ, que puede ser traducido como gente, humano o persona. Su lengua pertenece a la familia etnolingüística jê, del tronco macro-jê.

La sociedad A'uwẽ Xavante se organiza en múltiples sistemas dualistas que determinan la organización social, el parentesco, el matrimonio y la política, en un conjunto de 'mitades' que se entrecruzan. Uno de ellos son los clanes que dividen la comunidad en dos mitades exogámicas y patrilineales: por un lado, pö’redza'õnõ (girino) y, por otro, öwawẽ (agua grande). Los matrimonios solo se llevan a cabo entre las mitades y el clan es hereditario, que pasa de padres a hijos, por lo que la madre siempre será de un clan de la otra mitad.

De acuerdo con Graham (1993, p. 722), "la filosofía dualista xavante" organiza a las personas en otros tipos de mitades. Los A'uwẽ Xavante se dividen por franjas etarias organizadas jerárquicamente, desde los viejos hasta los jóvenes. Hay ocho clases de edad, cuatro para cada mitad. Las clases de edad se componen de los que han vivido juntos el período anterior al ritual de iniciación, unos cinco años, en la casa de los solteros, en lengua xavante hö, se iniciaron en el ritual de forma conjunta y se casaron en ceremonia colectiva.

\section{El proyecto Aldea Digital}

El proyecto Aldea Digital tiene como objetivo la educación mediática de los A'uwẽ Xavante de la aldea Sangradouro, ofreciendo talleres de creación de blogs, películas de animación, video documental y cartelería. Las actividades de los talleres incluyeron el registro, la documentación y la descripción escrita y audiovisual de las prácticas culturales del pueblo A'uwẽ Xavante y su posterior difusión, publicación y transmisión por internet. El objetivo de los talleres fue ofrecer formación y capacitación a los jóvenes de la aldea para la producción de sus propios medios de comunicación digitales. En términos globales, la finalidad era la inclusión digital de esta etnia indígena. 


\section{DISERTACIONES}

ESTUDIOS

Comunicación indigena en América Latina

ISSN: 1856-9536

Doi: http://dx.doi.org/10.12804/revistas.urosario.edu.co/disertaciones/a.5708

Volumen 11, Número 2 / Julio-diciembre 2018

Versión PDF para imprimir desde

http://revistas.urosario.edu.co/index.php/disertaciones

La tierra indígena (T. I.) xavante de Sangradouro tiene una superficie de aproximadamente 100000 hectáreas, donde viven cerca de 1660 personas distribuidas en 25 aldeas. La aldea Sangradouro es la mayor y principal aldea de la T. I. Fue fundada en 1957 por un grupo procedente de la T. I. xavante de Parabubure conducido por el líder Pedro Toroibu. ${ }^{1}$ La aldea está ubicada a $1,5 \mathrm{~km}$ de la carretera BR-070, en el km 225, y dista $53 \mathrm{~km}$ de la ciudad de Primavera del Leste. Según el último levantamiento realizado en 2010 por la Fundación Nacional del Indio (Funai), la población de la aldea Sangradouro era de 882 personas. Cerca de la aldea Sangradouro hay una aldea de la etnia bororo y una misión de la orden salesiana. La misión dista 700 metros de la aldea, tiene una iglesia y un edificio donde viven los sacerdotes, las monjas, y eventualmente hospeda invitados. Además, al lado de la misión, hay un puesto de salud y la Escuela Indígena San José, que ofrece educación primaria y secundaria.

Gran parte de los talleres se impartieron en el laboratorio de informática de la escuela indígena de la aldea Sangradouro. La escuela indígena de Sangradouro fue creada en 1957 por los salesianos. De 1957 a 1974 funcionó como colegio de internos. De 1975 hasta 1990 dejó de funcionar como internado, pero siguió coordinada por los salesianos. En 1991 la dirección de la escuela cambia para el Ministerio de la Educación de Brasil. Y, por fin, en 2006, los profesores y el director de la escuela son todos xavante. El centro dispone de un laboratorio de informática con cerca de 20 ordenadores, acceso a internet y un profesor A'uwẽ Xavante de informática llamado Natal Anhahö’a Tsere'ruremé Dutsã. Actualmente este laboratorio se utiliza para la enseñanza y las actividades educativas de la escuela, cuyas clases incluyen un curso básico en informática.

Los alumnos fueron los A'uwẽ Xavante de la aldea Sangradouro. En principio, hicimos una convocatoria general para toda la aldea e intentamos no limitar el número de alumnos de los talleres a un género, ni a una franja etaria, ni a un clan. A medida que el proyecto se fue desarrollando, se formó espontáneamente y de manera autogestionada un grupo de alumnos fijo. Ellos tenían conocimientos informáticos básicos, adquiridos en las clases de la escuela de la aldea.

El equipo del proyecto tuvo miembros fijos, trabajando en la gestión y organización, y participaciones puntuales en función de las necesidades del proyecto. Fue interdisciplinario y compuesto por profesores, funcionarios, técnicos y alumnos de la Universidad Federal de Goiás (UFG), de la Facultad de Información y Comunicación (FIC), de la Facultad de Artes Visuales y de la Facultad de Ciencias Sociales y Antropología. Yo coordiné el proyecto, pero siempre consultando a los A'uwẽ Xavante, tanto al equipo como al consejo de los hombres mayores, en cada nueva etapa. En este sentido, la coordinación intentó ser autogestionada y respetar la forma tradicional A'uwẽ Xavante de decidir, a partir de la consulta al consejo.

El proyecto, que todavía sigue en funcionamiento, se inició en el año de 2010. Fueron dos años de planificación (2010/11), seguidos por más de dos años de la realización de los talleres (2012/13) y desde 2014 hago el monitoreo de los medios de comunicación creados en los talleres. En 2012 y 2013, los talleres del proyecto fueron financiados por el Ministerio de la Educación (MEc) de Brasil en un programa de financiación de proyectos de extensión comunitaria para la implementación de políticas públicas de inclusión social. Una de sus líneas de financiación es la inclusión digital y étnica.

1 Para más información sobre la historia de la aldea Sangradouro, ver el documental de Divino Tserewahú llamado Sangradouro, disponible en la web del proyecto Video en las Aldeas: http://www.videonasaldeias.org.br/2009/video.php?c=76 


\section{DISERTACIONES}

ESTUDIOS

Comunicación indigena en América Latina

ISSN: 1856-9536

Doi: http://dx.doi.org/10.12804/revistas.urosario.edu.co/disertaciones/a.5708

Volumen 11, Número 2 / Julio-diciembre 2018

Versión PDF para imprimir desde

http://revistas.urosario.edu.co/index.php/disertaciones

\section{Metodología}

La metodología de la investigación tuvo como referencia central el método publicado en el libro Through Navajo eyes: an exploration in film communication and anthropology (Worth y Adair, 1972). Según Banks (2008), este trabajo es un modelo de investigación empírica bien diseñada, con objetivos y metodologías claros. Además de esta referencia clásica, la investigación utilizó múltiples métodos de trabajo de campo, como entrevistas, grupos focales, investigación-acción, observación participante y método etnográfico, con énfasis en el uso de la fotografía y del audiovisual como técnicas de observación en el campo.

En la investigación, hemos optado por la descripción y el análisis cualitativo del material. Hicimos el análisis del proceso de desarrollo de los medios de comunicación que se elaboraron en el marco del proyecto Aldea Digital, así como de los resultados y productos generados. En la interpretación de los resultados, reflexionamos y discutimos los conceptos de identidad y medio de comunicación xavante.

Los talleres se desarrollaron durante todo el año de 2012, con una periodicidad mensual, en los fines de semana y festivos. En julio de 2012 hicimos también un taller cuyas actividades fueron divididas entre la T. I. Sangradouro y la T. I. San Marcos, que dista $127 \mathrm{~km}$ de la primera. Por fin, en julio de 2013 hicimos un taller en el estudio de televisión y en la isla de edición de video de la Facultad de Información y Comunicación de la Universidad Federal de Goiás (FIC-UFG).

Los alumnos de los talleres fueron los A'uwẽ Xavante de la aldea Sangradouro, el grupo focal de la investigación. Este grupo fue compuesto por 15 hombres de la franja etaria entre 15 a 25 años, divididos en cuatro grupos.

Los talleres tuvieron como resultado la producción de un blog, un video documental, nueve animaciones de cortometraje en la técnica del stop-motion, dos marcas, una serie de carteles y un grupo en Facebook. En total, fueron trece talleres, pero no todos se utilizaron como fuente de información en la investigación. El corpus de análisis se limitó al material recogido en cinco de ellos: un taller de blog, de cartel, dos talleres de cine de animación con la técnica del stop-motion y uno de video documental. También analizamos el proceso de creación de dos marcas, del propio proyecto Aldea Digital y de la Organización de los Pueblos Indígenas Xavante (OPIX).

En el desarrollo de la investigación, los objetivos fueron expandidos debido al interés de otras etnias indígenas en participar de los talleres. Para atender a esta solicitud, hicimos también talleres en la aldea Argola de la T. I. Terena de Cachoeirinha y en la aldea Merure de la T. I. Bororo de Merure. En la investigación, delimité el análisis a los datos solamente de los Xavante.

\section{Mito e identidad A'uwẽ Xavante en los medios visuales}

Bartolomé (2006) identifica dos sistemas y discursos en la elaboración de la identidad indígena: "Uno se refiere a la naturaleza del 'nosotros' y el segundo, al nosotros confrontado con los 'otros” (2006, p. 40). Para Barth (1976), los grupos étnicos y las relaciones interétnicas dependen de la construcción y conservación de una frontera étnica y de la dicotomía entre miembros (yo) y extraños (otro). Por lo tanto, el artículo será dividido en dos partes. En un primer momento, presentamos el discurso A'uwẽ Xavante sobre 'nosotros' presente en los medios audiovisuales desarrollados en el proyecto Aldea Digital y enseguida la relación entre los A'uwẽ Xavante con los 'otros', específicamente los blancos. 


\section{DISERTACIONES}

ESTUDIOS

Comunicación indígena en América Latina

ISSN: 1856-9536

Doi: http://dx.doi.org/10.12804/revistas.urosario.edu.co/disertaciones/a.5708

Volumen 11, Número 2 / Julio-diciembre 2018

Versión PDF para imprimir desde

http://revistas.urosario.edu.co/index.php/disertaciones

La noción de persona y el discurso A'uwẽ Xavante sobre sí mismo se fundamenta en sus mitos del origen. Pretendemos demostrar que la noción de persona y el discurso A'uwẽ Xavante sobre sí mismo, presente en los medios audiovisuales desarrollados en el proyecto Aldea Digital, continúan fundamentándose en sus mitos del origen.

\section{Mito del origen del pueblo A'uwẽ Xavante}

En estos catorce años de investigación del pueblo A'uwẽ Xavante, oí muchas versiones de su mito del origen, ${ }^{2}$ contadas por personas y en situaciones distintas. La versión que presento fue narrada en A'uwẽ Xavante en el taller de cartel del proyecto Aldea Digital, por el anciano Francisco Pronhopa y traducida para el portugués por los alumnos del taller. ${ }^{3}$

El origen del pueblo A'uwẽ Xavante (Wapotó na'rada)

Antes de todo, era oscuro, no había ninguna nube, ni sol. Repentinamente aparecieron las nubes y un arco iris. Los hijos de las nubes, dos hermanos llamados Butsé y Urebe, bajan de las nubes por el arco iris a la Tierra.

Así empezaron a pensar en crear las mujeres. Entonces prepararon dos cilindros de la madera wamarĩ, como los pendientes usados por los hombres A'uwẽ Xavante. Butsé pintó las puntas de la madera de rojo. Urebe pintó una raya roja. Ellos pusieron los cilindros de madera en el suelo y los cubrieron con hojas de los árboles.

Al día siguiente, los dos cilindros se transformaron en dos mujeres. Butsé dio la mujer que él creó para Urebe y Urebe dio su mujer para Butsé. Butsé se casó con esta mujer llamada Tsinhotsẽéewawẽ. Tuvieron cinco hijos: Tsõrõpré, Tsõrõ'rada, Aptsi'ré, Tserebutuwẽ y Tsitóbné. Urebe se casa con la otra mujer llamada Petsi'ôtõrĩõ. También tuvieron cinco hijos: Tsa'amrĩ; Wéré'é, Tsitõmowẽ, Wadahité y Tsipadzabé.

A partir de ahí comienza la división entre los clanes. Butsé crea el clan pö' redza'õnõ y Urebe crea el clan öwawẽ.

Según los alumnos del taller, el anciano dijo que solo se acordaba de los nombres de los hijos varones de Butsé y Urebe. Faltaba identificar los nombres de las hijas mujeres. Pregunté a otros ancianos por estos nombres, pero nadie los recordaba.

Este mito explica muchas cosas de la identidad A'uwẽ Xavante. Los nombres y el origen de sus ancestros (cielo), el origen de las mujeres (cilindro madera) y el origen de los clanes, la división del pueblo A'uwẽ Xavante en dos clanes, la regla del matrimonio entre los dos clanes y el intercambio de mujeres por parte de los hombres.

La presencia del cilindro de madera en el mito merece destacarse. Conforme con Maybury-Lewis (1984), solo después de utilizar los pendientes cilíndricos es "que se pasa a la condición plena de hombres" (Maybury-Lewis, 1984, p. 314). Para Fernandes (2010, p. 455), los pendientes cilíndricos no son solo una condición para la formación de hombres plenos, más que esto, es la condición esencial para la persona A'uwẽ Xavante plena.

2 Como resultado de la investigación de mi máster, produje un documental que explora las relaciones entre el mito del origen y el ritual de iniciación masculino xavante. Video disponible en: https://www.youtube. $\mathrm{com} /$ watch?v=MtiFhsJnj7U

3 Para más publicaciones con otras versiones del mito del origen del pueblo xavante o sobre la mitología xavante en general, ver Giaccaria e Heide (1984, pp. 11-13), Maybury-Lewis (1984, pp. 220, 350), Medeiros (1991), Sereburã et al. (1998), Shaker (2002, p. 71), Falleiros (2012). 


\section{DISERTACIONES}

ESTUDIOS

Comunicación indigena en América Latina

ISSN: $1856-9536$

Doi: http://dx.doi.org/10.12804/revistas.urosario.edu.co/disertaciones/a.5708

Volumen 11, Número 2 / Julio-diciembre 2018

Versión PDF para imprimir desde

http://revistas.urosario.edu.co/index.php/disertaciones

Los hombres empiezan a utilizar este ornamento después de perforar sus orejas en el ritual de iniciación. Los pendientes cilíndricos colocados en los lóbulos de las orejas son símbolos del ritual de iniciación, un signo de la transición del soltero (wapté) a su nuevo estatus de joven recién maduro (ritéi'wa). Son una marca corporal y una señal de pertenencia al grupo. Solo la persona que tiene esta marca en su cuerpo puede ser considerado un miembro de la sociedad A'uwẽ Xavante. También representan la madurez sexual de sus miembros, una vez que se puede asociar esta penetración social de sus cuerpos con el sexo. Para Maybury-Lewis (1984, p. 314), los "dilatadores cilíndricos perforan los lóbulos de las orejas del iniciado de la misma manera que su pene [...] puede penetrar a una mujer". Los cilindros de madera del mito también ayudan a explicar la ceremonia de perforación de las orejas del ritual de iniciación. Los perforadores deben ser del clan opuesto al del joven que él deberá perforar la oreja. Después de perforada, él introduce un trozo del tallo de una planta pintada de rojo. Como en el mito, el perforador da el cilindro de madera pintado de rojo (simbolizando la mujer) a la persona del otro clan. Su objetivo principal sería la transmisión y actualización del modelo de persona, el ancestro presente en el mito, a los jóvenes que deben internalizarlo, incorporarlo, personificarlo y revivirlo.

Maybury-Lewis (1984) afirma que los A'uwẽ Xavante se comunican con sus parientes muertos a través de los pendientes cilíndricos. Propongo que esta comunicación no se restringe a los muertos y a sus ancestros. Los ancianos en Sangradouro decían que por la noche hablaban con el dios A'uwẽ Xavante, llamado Höimana'u'ö, y que el pendiente cilíndrico soplaba a sus oídos canciones y secciones que formaban parte de su sueño. Alexandre Tsereptsé me dijo en una ocasión: “Todo lo que pasó en mi vida yo lo vi antes, al pasar en mis sueños". Laura Graham (1986) también señala que los cantos colectivos, llamados daño're, se transmiten a través de los pendientes cilíndricos utilizados en los lóbulos de las orejas por los hombres iniciados.

Los alumnos del taller de cartel hicieron dibujos para representar visualmente sus ancestros del mito del origen. Además, escribieron el mito en xavante y en portugués. Dibujaron a los ancestros Butsé y Urebe, ornamentados como en los rituales A'uwẽ Xavante: utilizando la corbata tsõrebdzu, los pendientes cilíndricos y los símbolos de cada clan en la cara (Butsé con el símbolo del clan pöredza'õnõ y Urebe, con el öwawẽ, de la misma manera utilizado en la lucha del Oi'o). La gran mayoría representó a los ancestros con el motivo de pintura corporal llamado danhanapré (dañañapré) (Müller, 1976, p. 46; 2007, p. 138). Esta pintura consiste en un rectángulo rojo en el vientre y una banda roja en la línea de la columna, desde la cintura hasta el cuello. Este padrón de pintura es utilizado en momentos específicos del ritual de iniciación por los chicos que están siendo iniciados (wapté). En la carrera de la capa noni y en la carrera de la muerte o del veneno (tsa'urí'wa), en referencia a los desmayos de los corredores envenenados. En esa carrera, que discutiré en detalles más adelante en el apartado sobre el ritual de iniciación, los padrinos intentan lanzar un veneno a los jóvenes, que huyen. Pero la pintura no es exclusividad de la categoría de edad wapté. Es utilizada también por los hombres de todas las categorías de edad con el cargo ritual pahöri'wa y por los padrinos de los wapté de la categoría de edad danhohui'wa con el cargo ritual de perforadores de las orejas (daporedzapu'wa).

Otros alumnos dibujaron los personajes míticos con el motivo de pintura corporal llamado dauhö (Müller, 1976, p. 47; 2007, p. 138), que repite los rectángulos rojos en el vientre y en la columna, y añade en el resto del tronco, brazos y mitad del muslo la pintura negra. Este padrón de pintura es utilizado por los hombres de la categoría de edad danhohui'wa en la carrera con el tronco de la palmera del burití (uiwede) y en la distribución de comida en el día del pahöri'wa en el ritual de iniciación. También los representaron con el pelo preso atrás con una cola de caballo y el flequillo pintado de rojo, 


\section{DISERTACIONES}

ESTUDIOS

Comunicación indigena en América Latina

ISSN: 1856-9536

Doi: http://dx.doi.org/10.12804/revistas.urosario.edu.co/disertaciones/a.5708

Volumen 11, Número 2/ Julio-diciembre 2018

Versión PDF para imprimir desde

http://revistas.urosario.edu.co/index.php/disertaciones

utilizado en la ceremonia de la lucha con palos llamada Oi’ó. Por fin, algunos dibujaron a Butsé y Urebe sin ningún tipo de pintura corporal.
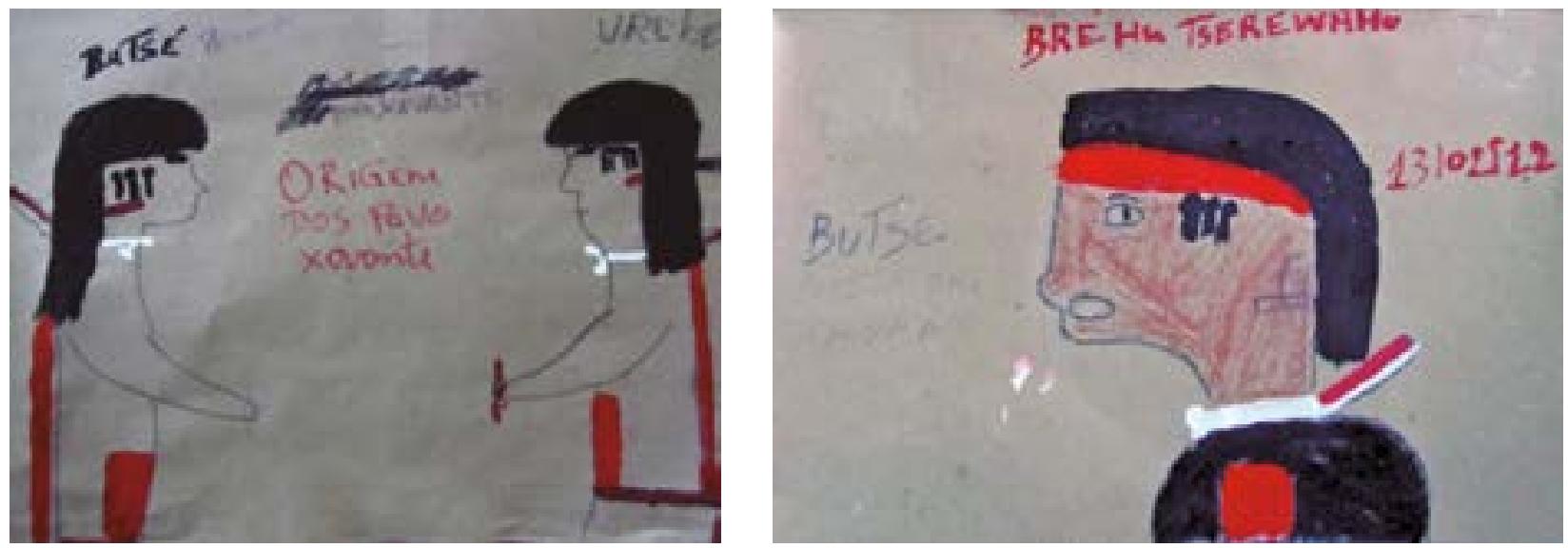

Figuras 1 y 2. Carteles con dibujos de los ancestros con la pintura corporal danhanapré (izquierda) y con la pintura corporal dauhö (derecha)

Fuente: archivo fotográfico personal.

La comparación entre el texto y los dibujos revela que hay informaciones presentes en los dibujos que no se encuentran en el texto y lo contrario. Los dibujos relacionan el mito con la pintura corporal utilizada en momentos específicos del ritual de iniciación, identifican los ancestros con cargos rituales y dentro del sistema de categoría de edad. Maybury-Lewis (1984) analiza un conjunto de narrativas presentes en la mitología A'uwẽ Xavante dedicadas al poder creador. En ellas, los personajes con esta capacidad son los wapté, asociados a poderes creativos. Pero la representación visual de los ancestros hecha por los alumnos en el taller no se limita a la categoría de edad wapté. Los ancestros fueron representados como wapté, danhohui'wa, pahöri'wa y daporedzapu'wa en diversos momentos y funciones del ritual de iniciación. En las carreras del noni, del tsa'uríwa y del uiwede, donde se necesita velocidad. Y como representantes de los cargos rituales pahöri'wa, el líder del ritual de iniciación, y daporedzapu'wa, el perforador de las orejas. Los cargos rituales proveen poder político y la velocidad, poder físico. Los resultados indican que los ancestros fueron representados por personas de la sociedad A'uwẽ Xavante con distintos tipos de poder: creador, político y físico.

\section{Ceremoniales e identidad A'uwẽ Xavante en los medios audiovisuales}

En 2013, los alumnos del proyecto Aldea Digital hicieron tres animaciones de ceremonias en los talleres en la Facultad de Información y Comunicación de la Universidad Federal de Goiás. Una de la carrera con el tronco de la palmera del burití, otra de una lucha semejante a la ceremonia llamada Oi'ó, pero entre un A'uwẽ Xavante contra un colonizador, $y$, por fin, del matrimonio. El proyecto también hizo un taller de cine documental en el que se produjo un video de cortometraje sobre la segunda parte del ritual A’uwẽ Xavante de iniciación masculino. 


\section{DISERTACIONES}

ESTUDIOS

Comunicación indigena en América Latina

ISSN: 1856-9536

Doi: http://dx.doi.org/10.12804/revistas.urosario.edu.co/disertaciones/a.5708

Volumen 11, Número 2 / Julio-diciembre 2018

Versión PDF para imprimir desde

http://revistas.urosario.edu.co/index.php/disertaciones

\section{Uiwede}

La carrera con el tronco de la palmera del burití, en xavante uiwede, es una carrera de relevos, se realiza como parte de los rituales de iniciación social, cosmológica (wai'á) y más recientemente como deporte. Se trata de una competición colectiva entre dos equipos, uno de cada clase de edad opuesta, donde los participantes tienen que cargar un trozo del tronco de la palmera del burití y pasarlo a su compañero de clase de edad. El trozo de tronco tiene aproximadamente $90 \mathrm{~cm}$ de longitud, llega a pesar $80 \mathrm{~kg}$ y es transportado en un trayecto de más o menos $8 \mathrm{~km}$. La carrera es una manera de desarrollar la fuerza y la resistencia física, dos cualidades muy valoradas por los A'uwẽ Xavante.

Las animaciones de las ceremonias presentan en el lenguaje del audiovisual otro aspecto de la construcción de la identidad social A'uwẽ Xavante, los procesos sociales de identificación. La animación del uiwede representa dos hombres de clases de edad opuestas, que identifican sus clases de edad a través de motivos de pintura corporal distintos. Uno con el motivo de pintura corporal llamado dauhö (Müller, 1976, p. 47; 2007, p. 138), ya presentado anteriormente. La pintura consiste en rectángulos rojos en el vientre y en la columna, y añade en el resto del tronco, brazos y mitad del muslo la pintura negra. Es el padrón utilizado por los hombres de la clase de edad más vieja y de la categoría de edad danhohui'wa. Y la clase de edad más joven fue representada en la animación pintada de rojo con un rectángulo negro en el vientre. El proceso social de identificación de las personas con una determinada clase de edad hace parte de la construcción de la identidad social A'uwẽ Xavante. Se nota aquí la misma cuestión que presentaremos en el ritual de iniciación y la carrera del noni. La diferencia es que en la carrera del burití (uiwede) hay disputas entre diferentes clases de edad y en la carrera del noni entre las categorías de edad.

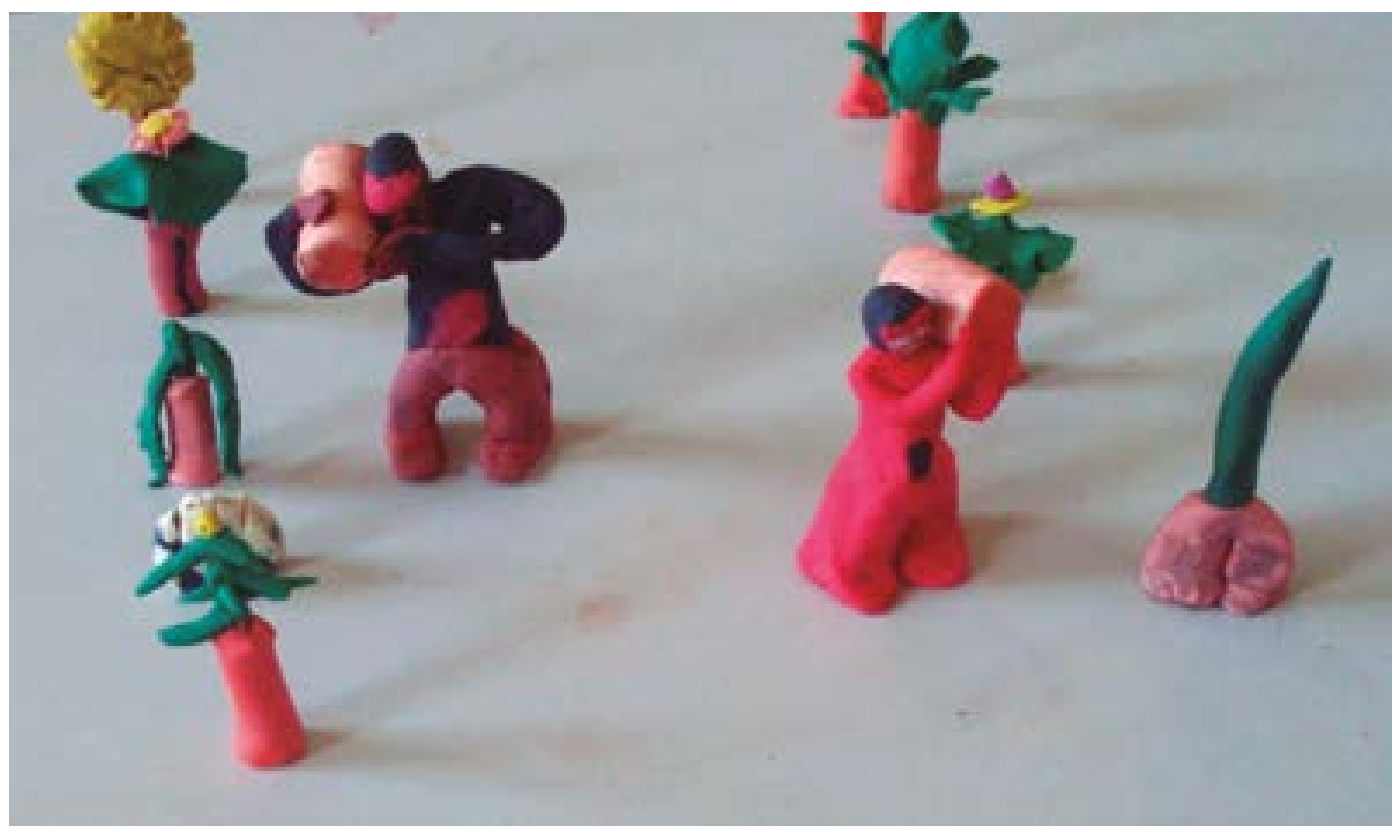

Figura 3. Frame de la animación del uiwede

Fuente: archivo audiovisual personal. 


\section{DISERTACIONES}

ESTUDIOS

Comunicación indigena en América Latina

ISSN: $1856-9536$

Doi: http://dx.doi.org/10.12804/revistas.urosario.edu.co/disertaciones/a.5708

Volumen 11, Número 2 / Julio-diciembre 2018

Versión PDF para imprimir desde

http://revistas.urosario.edu.co/index.php/disertaciones

Hay una relación directa entre el uiwede y el mito del origen del fuego. El mito cuenta que después del robo del fuego, la leña con fuego fue pasada de hombro en hombro, como en el uiwede. En las diversas versiones del mito se encuentran referencias directas a la carrera del burití. El mito habla que el robo del fuego fue el origen de la carrera. En este sentido, la carrera es una forma de actualizar y revivir ritualmente el mito.

\section{Ritual de iniciación masculino A'uwẽ Xavante}

Un producto audiovisual de un ritual desarrollado en el proyecto fue un documental de cortometraje sobre la segunda parte del ritual A'uwẽ Xavante de iniciación masculino. El ritual de iniciación marca la transición de los adolescentes a la edad adulta y su reconocimiento como hombres. El rito de paso modifica el estatus social de este grupo de personas, o sea, su condición relacional y la identidad social.

El ritual de iniciación fue realizado en otra tierra indígena xavante llamada San Marcos. En la etapa de planeamiento del taller, Natal comentó que sería bueno tener un anciano acompañando al equipo e invitó a su padre José Tsere'ruremé. José es un wamarĩtede'wa. Trátase de un cargo de jefatura A'uwẽ Xavante y una de sus funciones es pacificar los conflictos. Además, él quería aprovechar el viaje para visitar a su hermano que vive en esta aldea. Al principio, no comprendí la importancia de su presencia. Pero durante el taller sus intervenciones fueron fundamentales en momentos estratégicos de negociación de disputas entre las personas de la aldea San Marcos y los miembros del proyecto de la aldea Sangradouro.

Llegando a San Marcos, la primera tarea fue presentarnos en el centro de la aldea (warã) delante el consejo de los hombres adultos y solicitar autorización de la comunidad para filmar el ritual. Presentamos el proyecto y sus objetivos principales. Después de hablar, el señor José hizo la traducción en xavante. Los hombres preguntaron qué íbamos a hacer con las imágenes grabadas, en dónde se iban a exhibir, y cuestionaron si teníamos algún interés económico de ganar dinero con las grabaciones. Al final, fuimos autorizados a filmar después de asumir en público el compromiso ético con los usos que se harían de las imágenes.

En el proceso de edición, el profesor Divino hizo la sugerencia de adicionar una presentación del equipo del proyecto. El documental empieza con esta presentación personal, seguida de tres pantallas de intertítulos que exponen el proyecto, indicando cuándo, dónde y quién hizo el video. La primera parte del documental enseña lo que se podría llamar el making-of del ritual, el detrás de cámaras. El viaje para recoger hojas para la capa noni y luego su producción. La inserción de los momentos de preparación del ritual en el documental indica la importancia de estas partes en el ritual. Para una persona no acostumbrada con el ritual, se podría pensar que solo aquello que se muestra en público en el centro de la aldea es importante o hace parte del ritual. La preparación es una parte relevante del ritual y no sería distinto en el documental. En este sentido, el documental confirma que en la cultura A'uwẽ Xavante no hay distinción entre proceso y producto. Todo es un proceso: el ritual, la identidad, la cultura y también la producción del video. Y tampoco hay una jerarquía entre proceso y producto. Ambos son igualmente importantes. En la concepción A’uwẽ Xavante, este proceso tiene que mostrarse de forma explícita en el producto final.

Solamente a partir de la mitad del documental es que se muestran las carreras del noni. El video tiene el cuidado de enseñar todos los tipos de disputas que ocurren en la carrera. En primer lugar, disputas internas entre los jóvenes que estaban siendo iniciados, de la categoría de edad wapté. Luego, entre los wapté contra los iniciados 
en el ritual anterior, de la categoría de edad ritéi'wa, considerados sus enemigos rituales. Y, por fin, entre los wapté contra sus 'padrinos', de la categoría de edad danhohui'wa. Además de las disputas entre estos grupos, también fueron hechas disputas dobles entre personas de la misma y otras categorías de edad. Muchos alumnos dividieron su tiempo y dedicación entre sus funciones y actividades en el proyecto, como el registro del ritual, con su participación en las carreras para representar sus respectivas categorías de edad. Ellos no se limitaron a simplemente observar y registrar el ritual, sino que también participaron activamente en ello. El proceso social de identificación de los jóvenes con una determinada categoría de edad se destaca en el video como una parte importante de la construcción de la identidad social A'uwẽ Xavante.

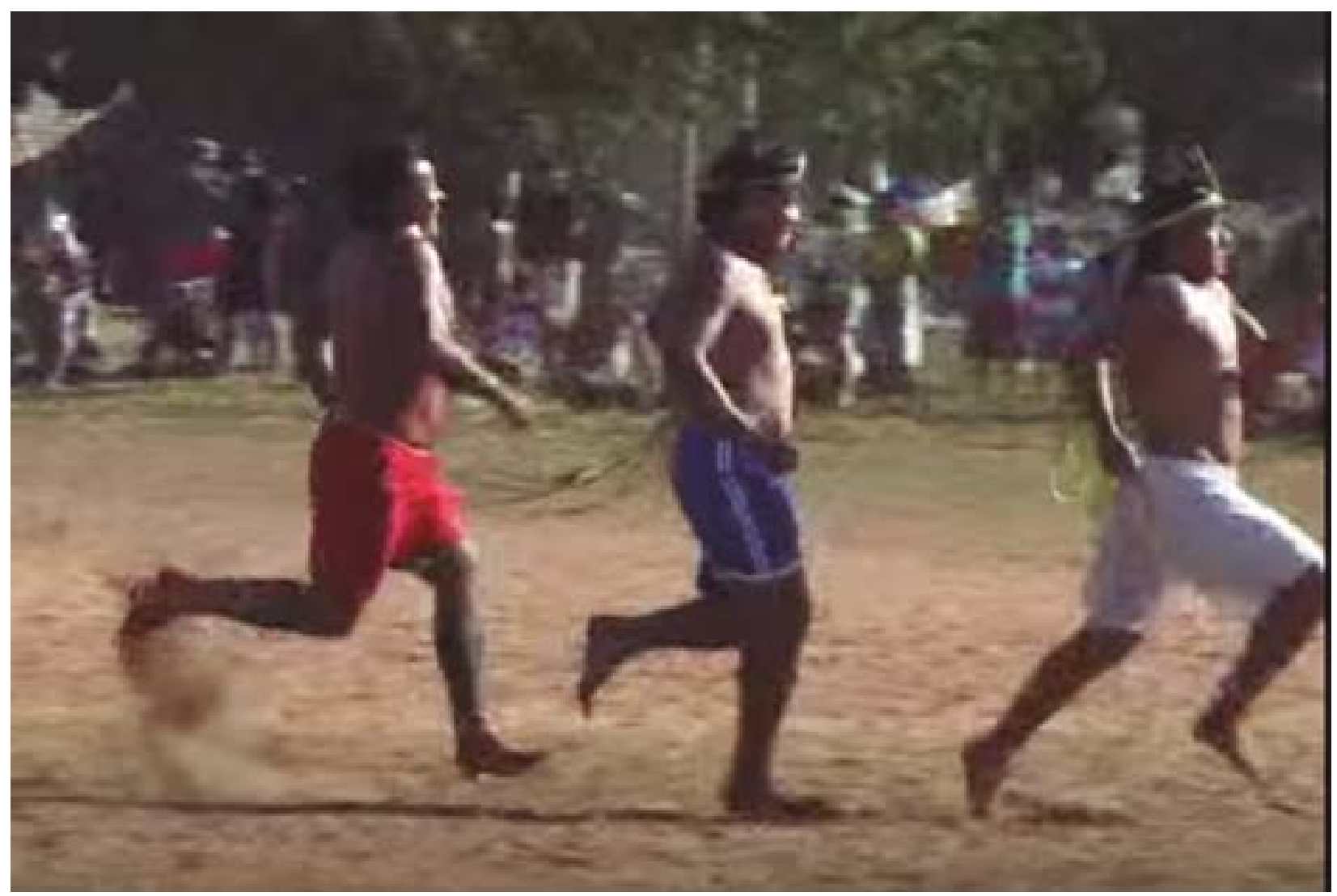

Figura 4. Frame del documental con las carreras del noni

Fuente: archivo audiovisual personal.

Spaolonse (2006, p. 47) destaca que, para cada fase del ritual de iniciación, el grupo de edad en la categoría wapté recibe sucesivas denominaciones que demuestran el carácter temporal de su identidad social. Y Welch (2010, p. 252) afirma que la identidad A'uwẽ Xavante es múltiple, "cada formulación de la identidad tiene su lugar y tiempo", y los individuos "tienen autonomía para construir estas formulaciones como lo deseen". Según el autor: 


\section{DISERTACIONES}

ESTUDIOS

Comunicación indigena en América Latina

ISSN: 1856-9536

Doi: http://dx.doi.org/10.12804/revistas.urosario.edu.co/disertaciones/a.5708

Volumen 11, Número 2 / Julio-diciembre 2018

Versión PDF para imprimir desde

http://revistas.urosario.edu.co/index.php/disertaciones

Las relaciones multidimensionales de jerarquía y de oposición, que en muchos aspectos unen y separan a los individuos en una sociedad, resaltan una característica presente en la sociabilidad xavante: no hay un único punto de referencia para la construcción de categorías inclusivas o exclusivas de identidad. Toda persona de fuera es al mismo tiempo también una persona de dentro. Cada igual es también una persona mayor o menor. El estatus no es absoluto y no es fijo; él es contingente, transitorio y circunstancial (Welch, 2014, p. 172).

El documental termina con el canto/danza de los padrinos llamada Wanoridobe. Esta canción, decían los A'uwẽ Xavante, es como el himno del ritual, una vez que se trata del único canto que se repite en todos los rituales de iniciación. El resto de las músicas cambia de un ritual al otro. Según la etnografía del ritual (Coelho, 2007), la estructura de este canto/danza se divide en tres partes: siempre en círculo y con las manos dadas. En primer lugar, los 'padrinos' y 'madrinas' bailan caminando hacia la izquierda y la derecha, golpeando los pies con fuerza en el suelo. A continuación, el baile y el canto se aceleran, y se inicia un rápido giro saltando todos sincrónicamente, quitando los dos pies de la tierra, mientras que el canto toma un carácter más rítmico y menos melódico que en su primera parte. Y finalmente ralentizan, con el canto volviendo a una forma predominantemente melódica y la danza, que consiste en elevar la rodilla a la altura de la cintura, alternando las piernas.

Todas las escenas del documental son acompañadas por explicaciones de los A'uwẽ Xavante en su lengua sobre lo que pasa. Las entrevistas tienen un nivel de intimidad que solo fue posible en función de las relaciones personales de los miembros del equipo con los entrevistados y del dominio del idioma xavante. Las imágenes indican que la función de la camera en el documental es puramente descriptiva. No tuvimos tiempo en el taller de hacer los subtítulos de las entrevistas en lengua xavante. La ausencia de los subtítulos destaca dos cuestiones. Por un lado, señalan que el público del documental es el propio pueblo A'uwẽ Xavante. Por otro, pone en evidencia una vez más la importancia del proceso en detrimento del producto. Para el público A'uwẽ Xavante, el video es relevante como un registro de los rituales. No hace falta que estos registros sean finalizados en un producto con subtítulos.

\section{Política de la identidad A’uwẽ Xavante}

Después de los discursos A'uwẽ Xavante sobre sí mismo y su autorrepresentación en los medios, presentaremos ahora el discurso sobre su identidad a partir del contraste y la oposición con los 'otros' y blancos.

\section{Oi’ó}

Otra animación de ceremonias es muy interesante para pensar la relación entre los A'uwẽ Xavante y los 'otros'. Es un objeto de análisis privilegiado para reflexionar sobre el proceso de construcción de la identidad cultural A'uwẽ Xavante en su relación con el blanco. La animación es la representación de una lucha entre un A’uwẽ Xavante, llamado en la animación 'gorro', contra un colonizador, que en el período del Brasil colonial se llamaba bandeirante. La lucha representada en la animación es muy semejante al ceremonial A'uwẽ Xavante llamado Oi'ó, que consiste en una disputa entre dos niños de clanes opuestos que se golpean con sus palos. En la animación, al revés de una lucha entre dos niños de clanes opuestos, fue hecha una lucha entre un A'uwẽ Xavante contra un blanco, el colonizador, el waradzu. El A'uwẽ Xavante tiene su cuerpo pintado con el motivo de pintura corporal llamado dauhö 


\section{DISERTACIONES}

ESTUDIOS

(Müller, 1976, p. 47; 2007, p. 138). La pintura, presentada anteriormente, está compuesta de dos rectángulos rojos, uno en el vientre y otro en la columna. El resto del tronco, brazos y mitad del muslo son pintados de negro. En el Oi'ó, es el padrón de pintura corporal utilizada por los miembros del clan öwawẽ. Lleva también en las manos un palo de madera, como el utilizado en el Oi'ó. El waradzu fue representado con un muñeco de color negro. Solamente el A'uwẽ Xavante tiene un palo. En la animación, el A'uwẽ Xavante golpea al blanco, que cae al suelo. Enseguida viene un camión que lo recoge y se lo lleva.

Llama la atención la sustitución en la animación del niño del clan pö'redza'õnõ por el blanco. La animación de la lucha entre el A'uwẽ Xavante del clan öwawẽ y el blanco presenta al blanco como el enemigo, en un tipo de oposición. En la animación el blanco está en el lugar de un miembro de la mitad y del clan opuesto. Desde el punto de vista de las mitades clánicas y de la lucha entre ellas en el Oi'ó, el blanco representa un nuevo tipo de oposición. En el mito de origen del waradzu, el mar divide a los A'uwẽ Xavante en dos mitades. De un lado del mar se quedan los A'uwẽ Xavante, del otro el ancestro A'uwẽ Xavante, que se transforma en blanco. Elizabeth Ewart (2013) también afirma que los panará, otra comunidad indígena del grupo jê, consideran a los blancos como una mitad opuesta. El concepto de identidad contrastiva de Cardoso de Oliveira (1976) manifiesta que esta noción de identidad trabaja por oposición entre el nosotros y los otros, entre el yo y el otro, no existe por sí sola, ya que nace de este juego.

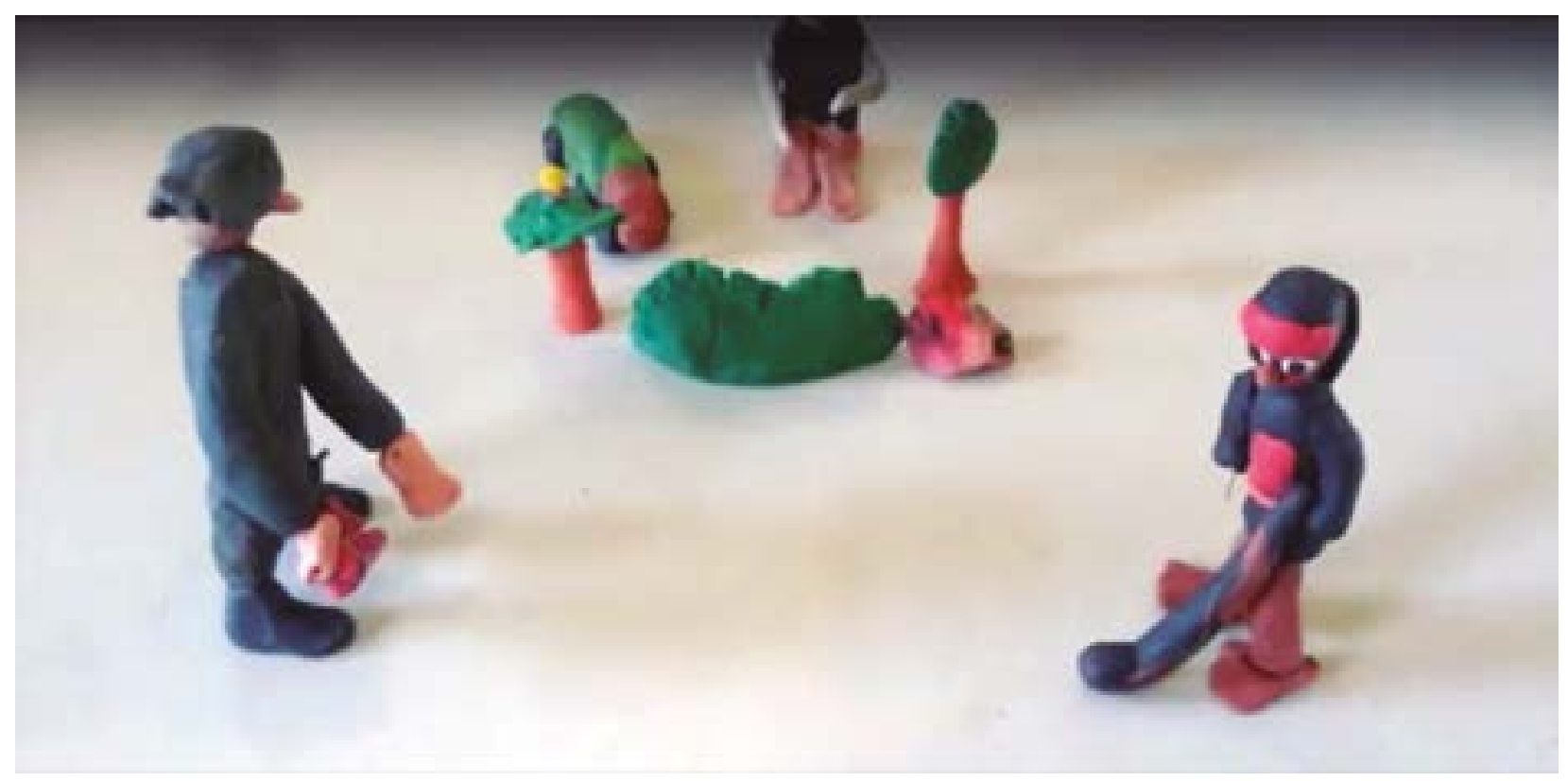

Figura 5. Frame de la animación de la lucha del Oi’ó

Fuente: archivo audiovisual personal. 


\section{DISERTACIONES}

ESTUDIOS

Comunicación indígena en América Latina

ISSN: 1856-9536

Doi: http://dx.doi.org/10.12804/revistas.urosario.edu.co/disertaciones/a.5708

Volumen 11, Número 2 / Julio-diciembre 2018

Versión PDF para imprimir desde

http://revistas.urosario.edu.co/index.php/disertaciones

\section{Identidad personal A'uwẽ Xavante}

Maybury-Lewis asevera que "un hombre xavante debe tener, teóricamente, como mínimo cuatro nombres” (1984, p. 298), aunque la gran mayoría de los hombres no llega a edad adulta con tantos nombres. Tener un nombre o muchos es una señal de madurez. Los hombres A'uwẽXavante reciben un nombre para cada fase de la vida, de manera que parece ser más importante la mudanza que los propios nombres. El cambio de los nombres masculinos indica el estatus social de su detentory el pasaje de una categoría de edad a otra. Los cambios significan "la preocupación de los xavante con el marcar cada una de las fases de la construcción del hombre [...] un hombre es fruto de conquistas sucesivas, de alteraciones intrínsecas que van formando, poco a poco, el ser" (Lopes da Silva, 1986, p. 250, las cursivas son nuestras). Los nombres están asociados a posiciones sociales, de modo que un nuevo estatus exige otro nombre. La transmisión de los nombres entre las generaciones de una familia concede al nuevo portador el estatus de su antecesor. Pero los clanes, linajes y mitades no tienen el privilegio a nombres exclusivos. Los criterios para la descendencia de los nombres pueden ser el parentesco, las clases y categorías de edad, y las facciones políticas. "El primer nombre de un chico marca su contacto con el mundo sobrenatural: el de los espíritus de los parientes patrilineales muertos, cuyo nombre es revivido en la transmisión" (Lopes da Silva, 1986, p. 251). Mientras que el nombre del rapaz (ritéi'wa) viene por la línea materna. Los nombres personales A'uwẽ Xavante, "de un lado, remiten para fuera, para el mundo natural o sobrenatural; de otro, remiten para dentro de la persona, constituyéndose en uno de sus elementos formadores" (Lopes da Silva, 1986, p. 252). En el cotidiano, muchos términos son utilizados con más frecuencia que los nombres personales: primero los de parentesco, después las clases de edad y, por fin, las terminologías rituales. "La identificación de los individuos por los xavante es hecha a través de la combinación de varios sistemas de clasificación, sobresaliendo el de clases de edad, la filiación a las mitades clánicas y las relaciones de parentesco" (Lopes da Silva, 1986, p. 151).

Según Lopes da Silva (1986), el nombre está relacionado con el prestigio y es la "expresión concreta de la consciencia de una identidad personal" (Lopes da Silva, 1986, p. 87, las cursivas son nuestras). "Los conceptos de identidad y continuidad son primeramente transmitidos a los xavante dentro del grupo doméstico donde nace [y] aprende a reconocer como iguales a los miembros del grupo de ascendencia paterna común a la que pertenece" (Lopes da Silva, 1086, p. 250). La persona teje las diversas partes que componen la sociedad A'uwẽ Xavante, incorpora e iguala en sí conceptos únicos expresados por los 'otros' y muchas veces opuestos. El "sistema de nominación direccionado a la construcción de la persona marca su individualidad [...] a través del uso del nombre como eslabón de ligación entre hombres de mitades y generaciones diversas" (Lopes da Silva, 1986, p. 248). Los nombres personales A'uwẽ Xavante son medios de identificación temporal de individuos, marcando las fases de la vida de los hombres. Para la autora, los nombres propios y cargos ceremoniales pahöri'wa, tebe y aihöubuní "son los únicos que pueden ser considerados 'títulos' relativos a un 'lugar en la sociedad', indicadores de un 'personaje”, como decía Mauss (2003, pp. 372-382).

Según se puede comprobar en el trabajo de campo, los alumnos del proyecto Aldea Digital tienen nombres en portugués junto con los términos de parentesco. El contacto con los blancos creó la necesidad de hacer el certificado de nacimiento, donde se pone primero el nombre en portugués y después el nombre de su familia para identificar a los individuos. El registro de nacimiento limita la tradición A'uwẽ Xavante de cambiar y tener muchos nombres. Así, hay una transformación en la identidad personal A'uwẽ Xavante y la creación de nuevas identidades 'híbridas'. 


\section{DISERTACIONES}

ESTUDIOS

Comunicación indigena en América Latina

ISSN: 1856-9536

Doi: http://dx.doi.org/10.12804/revistas.urosario.edu.co/disertaciones/a.5708

Volumen 11, Número 2 / Julio-diciembre 2018

Versión PDF para imprimir desde

http://revistas.urosario.edu.co/index.php/disertaciones

La comparación entre el nombre de los alumnos del proyecto Aldea Digital en sus certificados de nacimiento con el nombre en sus perfiles personales del Facebook revela que la gran mayoría utiliza el nombre del certificado en su perfil personal. La política de nombres del Facebook exige la utilización del nombre real en el perfil personal. Pero hay también casos en que las personas utilizan sus nombres personales en portugués, seguidos del nombre de su etnia. Este es el caso, por ejemplo, de Natal, que tiene dos perfiles: el primero con el mismo nombre de su certificado de nacimiento (Natal Anhahö'a Tsere'ruremé Dutsã) y el segundo, con su nombre portugués y el nombre de su grupo étnico (Natal Anhahö’a Xavante). Así como Natal, otros integrantes del proyecto también tienen dos perfiles personales. Para determinadas publicaciones ellos utilizan el perfil con la identidad y el nombre del parentesco; para otras, el perfil con su identificación étnica. Para publicaciones más 'personales', privadas y para relacionarse con amigos y parientes, Natal utiliza el perfil con el nombre del nacimiento. Para publicaciones públicas, políticas, como presidente de la opIx, sus actividades activistas y del proyecto Aldea Digital, él utiliza el perfil con el nombre de su etnia. Incluso su actual fotografía de este perfil es la publicidad de su campaña electoral como candidato a concejal.

El hecho de tener dos perfiles personales revela una relación directa con la tradición A'uwẽ Xavante de cambio de nombres. Esta dupla identidad en el Facebook (así como la relación entre los personajes en los mitos) es la continuidad de la tradición A'uwẽ Xavante de cambiar de nombre. O quizá sea otra evidencia de la costumbre A'uwẽ Xavante de cambiar de identidad en función del contexto, hecho presentado anteriormente y también notado por otros autores sobre la identidad A'uwẽ Xavante. La autorrepresentación de los A'uwẽ Xavante en los nombres de los perfiles personales de Facebook es la continuidad de la tradición de los cambios de nombres y de la dupla identidad de los personajes en la mitología A'uwẽ Xavante.

\section{Identidad visual del proyecto Aldea Digital}

El último objeto de análisis del artículo es la marca del proyecto Aldea Digital. La marca fue desarrollada de forma colectiva, colaborativa y participativa entre los miembros blancos y A'uwẽ Xavante del equipo del proyecto. La primera versión de la marca fue hecha por los becarios del proyecto bajo mi coordinación. Tenía como objetivo representar las cuatro etnias participantes en el proyecto (A'uwẽ Xavante, bororo, terena y krahô). Fue inspirada en los grafismos indígenas presentes en el libro Grafismo indígena: estudos de antropologia estética (Vidal, 2007). De modo general, los grafismos indígenas utilizan formas geométricas. Cuando presenté la propuesta en Sangradouro para los A'uwẽ Xavante del equipo del proyecto, ellos me preguntaron: “¿Qué significa el símbolo cuadrado del medio?". Contesté: “Es como una aldea". Y ellos dijeron: "Pero nuestra aldea es redonda, circular". Yo les expliqué que la idea no era que fuese igual a la aldea A'uwẽ Xavante, sino una forma geométrica para representar las aldeas de las cuatro comunidades del proyecto. No los convencí. Ellos me pidieron lápiz y papel, y empezaron a hacer dibujos de una aldea circular. La versión final adoptada en el proyecto fue el resultado de estos dibujos hechos en la aldea. 


\section{DISERTACIONES}

\section{ESTUDIOS}
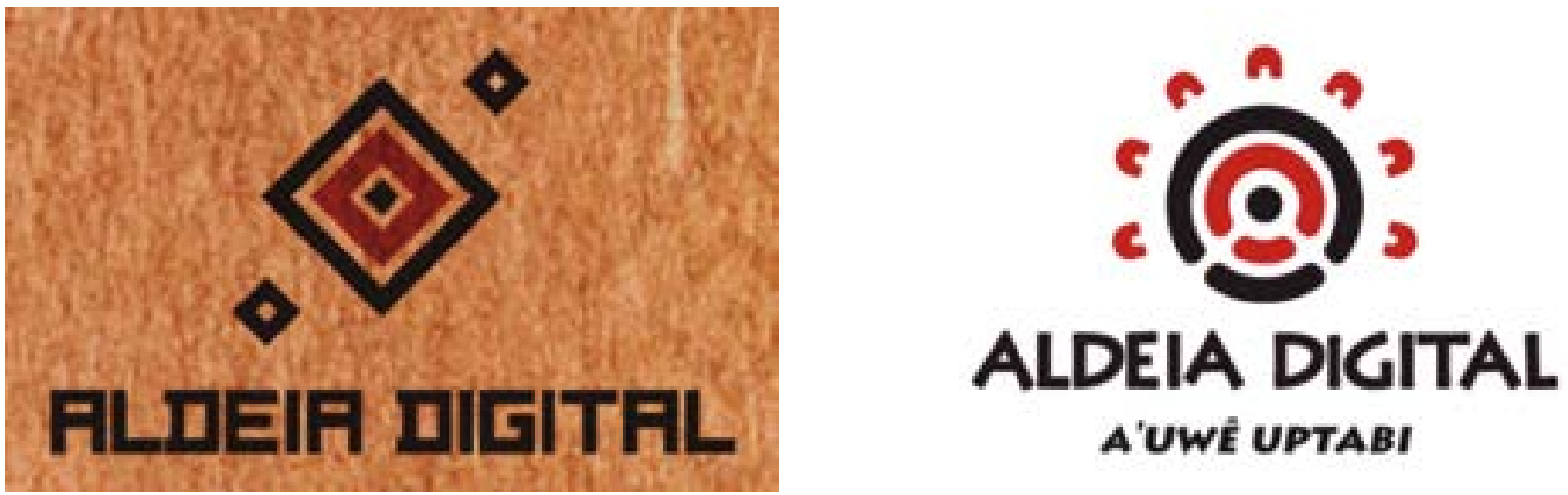

Figuras 6 y 7. Marca del proyecto Aldea Digital

A la izquierda, la propuesta presentada en la aldea. A la derecha, la versión final.

Fuente: archivo iconográfico personal.

El cuestionamiento hecho por los A'uwẽ Xavante en este día en la aldea tornó visible el conflicto comunicacional y político entre la hetero y la autorrepresentación. Según Canevacci (2001), la cuestión de "quién-representaquién", "quién representa y quién es representado", es el punto central de la tensión presente en las relaciones de poder involucradas en el proceso de negociación de la representación. De modo general, la heterorrepresentación que los blancos y los medios de comunicación masivos hacen de los pueblos indígenas es estereotipada, como nos muestra la reacción de los A'uwẽ Xavante delante de la primera versión de la marca presentada en la aldea. El intento del proyecto de representar una aldea 'genérica' fue cuestionado y corregido por los A'uwẽ Xavante. El indio genérico no existe, es y siempre fue una creación del blanco.

Para Geertz (1997), las formas de autorrepresentación son un objeto de estudio privilegiado para la comprensión de la identidad de un pueblo. La autorrepresentación visual que los A'uwẽ Xavante hicieron de su comunidad y aldea en la marca del proyecto tiene muchos sentidos. Por un lado, ella cuestiona la heterorrepresentación que nosotros, los blancos, hicimos de ellos. Por otro, ella resignifica la ideología A’uwẽ Xavante del espacio social y la aldea como un signo emblemático.

De acuerdo con Graham (1986, p. 84), la aldea semicircular A'uwẽ Xavante expresa la división entre la esfera femenina y masculina. El espacio femenino consiste en los grupos domésticos que componen el semicírculo de las casas en la periferia de la aldea. El masculino es el espacio central donde se ubica el punto de encuentro público y político (warã) de los hombres maduros. Para Maybury-Lewis (1984, p. 231), la organización espacial de la aldea A'uwẽ Xavante no representa de modo explícito las múltiples divisiones internas de su sociedad, como, por ejemplo, entre otras comunidades indígenas del Brasil central, como los bororo (Lévi-Strauss, 2008), los timbira (Nimuendajú, 1946, p. 79) o los xerente (Nimuendajú, 1942, p. 17). Pero la página web ${ }^{4}$ creada por una ONG A'uwẽ Xavante llamada IDETI afirma que la aldea de Pimentel Barbosa está dividida en dos, del lado derecho están las casas de las familias del clan pörredza'õnõ y del lado izquierdo las del clan öwawẽ. Independiente de las diferencias, hay una cosa en común

4 En: http://www2.uol.com.br/aprendiz/designsocial/xavante/frame_nvida.htm 


\section{DISERTACIONES}

ESTUDIOS

entre las aldeas de los grupos indígenas pertenecientes a la familia etnolingüística jê, el círculo. Las aldeas jê son siempre circulares. Tres de las cuatro etnias participantes en el proyecto son clasificadas como jê, los A'uwẽ Xavante, los bororo y los krahô. Sin darnos cuenta, los A'uwẽ Xavante nos enseñarán una característica común entre las comunidades participantes del proyecto: el formato de sus aldeas. El indio genérico no existe, pero la marca hecha por los A'uwẽ Xavante nos permite identificar un elemento común entre los tres grupos jê.

La superposición de la marca del proyecto sobre la imagen aérea de satélite de la aldea Sangradouro demuestra una coincidencia de la cual no teníamos consciencia en el período de los talleres. La marca no solo tiene el formato circular de la aldea como corresponde a un diagrama o a la planta de la propia aldea. Tradicionalmente, el semicírculo de las aldeas A'uwẽ Xavante tiene una abertura en dirección al río, lo que se podría considerar el punto de conexión entre el exterior y el interior. La entrada del 'espacio exterior' para adentro de la aldea y la salida de la aldea para el exterior. La aldea Sangradouro ya no tiene esta forma tradicional de herradura, actualmente es un círculo completo cerrado. Además de las casas distribuidas en el círculo exterior, hay más casas ubicadas dentro del círculo, casi formando un segundo círculo interno. Pero, para los A'uwẽ Xavante, el mapa mental de la aldea Sangradouro sigue siendo en el formato 'tradicional' de herradura, como lo demuestra la representación de la aldea en la marca. La identidad visual del proyecto Aldea Digital mezcla el mapa de la aldea 'tradicional' A'uwẽ Xavante con el símbolo del wifi de la comunicación digital. En la marca, el símbolo del wifi fue inserido exactamente en el local de la abertura al río. En este sentido, la marca es el resultado de la yuxtaposición del símbolo del wifi con el diagrama 'tradicional' de la aldea.
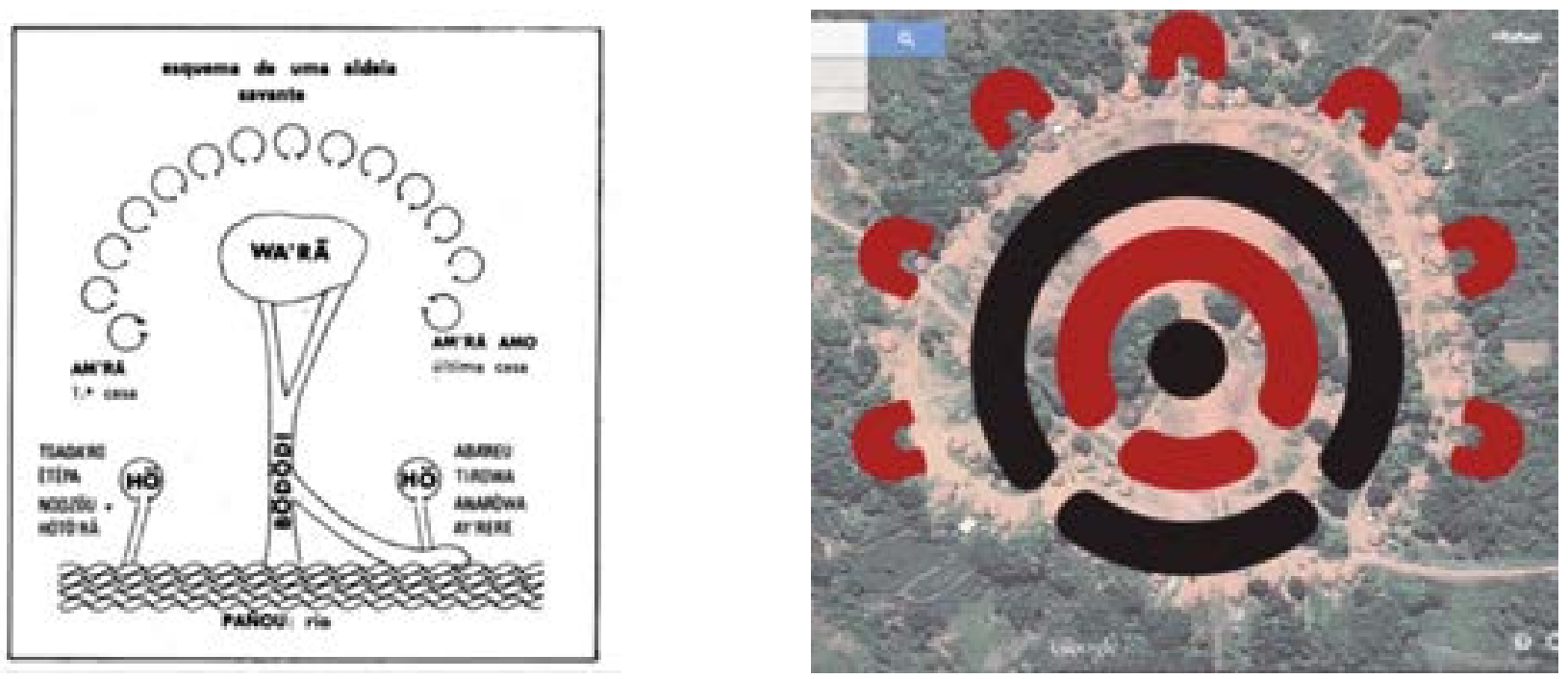

Figuras 8 y 9. Aldea A'uwẽ Xavante

A la izquierda, diagrama de una aldea A'uwẽ Xavante. A la derecha, la superposición de la marca del proyecto sobre la imagen de satélite de la aldea Sangradouro.

Fuentes: planta de la aldea A'uwẽ Xavante (Giaccaria y Heide, 1984, p. 56); imagen aérea de la aldea Sangradouro (Google Maps, recuperada de https://www.google.com/maps/place/15³8'48.4" S+53'54'20.8 "W/@-15.6469007,-53.9060923,659m/data=!3m1!1e3!4m2!3m1!1s0x9370c621faf26d99:0xb3183631d9fea406); marca del proyecto: archivo personal. 


\section{DISERTACIONES}

ESTUDIOS

Comunicación indigena en América Latina

ISSN: 1856-9536

Doi: http://dx.doi.org/10.12804/revistas.urosario.edu.co/disertaciones/a.5708

Volumen 11, Número 2 / Julio-diciembre 2018

Versión PDF para imprimir desde

http://revistas.urosario.edu.co/index.php/disertaciones

La marca representa visualmente y de manera esquemática la relación entre la cultura A’uwẽ Xavante y la cultura de los blancos, entre el 'nosotros' y 'ellos'. El resultado de esta interacción es una identidad 'híbrida'. Hay una inversión en las relaciones de poder presentes en el proceso de representación. La ciudad no es más el centro desde donde emana la información y sí el centro de la aldea, el espacio público, masculino y político. Para Lopes da Silva (1986, p. 147), "según la ideología masculina [y] la concepción de los xavante [...] los hombres son los depositarios de la cultura y de la tradición". La marca tiene la capacidad de representar visualmente el concepto de identidad que se fue desarrollando en el transcurso del capítulo: la identidad A'uwẽ Xavante en los medios audiovisuales es 'híbrida', resultado de un proceso, y su transformación contextual trasciende las limitaciones culturales.

\section{Conclusiones}

Como demuestran los resultados en diversas partes del artículo, no son los A'uwẽ Xavante los que se transforman en blancos y sí los blancos en A'uwẽ Xavante. Este hibridismo no es solamente el producto del contacto con los blancos. Él se encuentra en la propia concepción A'uwẽ Xavante de identidad, evidente en los medios de los mitos y rituales, conforme fue presentado en el artículo. El cambio de los nombres y de las categorías de edad, la transformación como principio básico de la mitología A'uwẽ Xavante y los múltiples procesos sociales de identificación presentes en los rituales y en la vida social.

El análisis de la construcción de la identidad A'uwẽ Xavante en los medios audiovisuales nos permite identificar cinco diferentes procesos: 1) identidad étnica: la noción de persona y el discurso A'uwẽ Xavante sobre 'nosotros', presente en los medios audiovisuales de los mitos, transmiten y actualizan el modelo de persona, los ancestros, a los jóvenes que deben internalizarlo, incorporarlo y revivirlo; 2) identidad social: los múltiples procesos sociales de identificación presentes en los medios audiovisuales de los ceremoniales que identifican las personas con una determinada clase y categoría de edad; 3 ) identidad cultural: la política de la identidad A'uwẽ Xavante, a partir del contraste y la oposición con los 'otros' y la conservación de una frontera con los blancos; 4) identidad personal: la identidad digital A'uwẽ Xavante en el Facebook como la continuidad de la tradición A'uwẽ

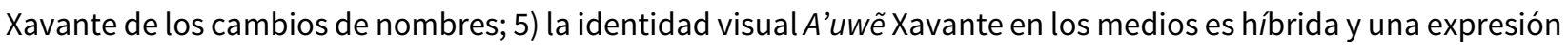
política de la identidad cultural A'uwẽ Xavante.

\section{Referencias}

1. Barth, F. (Comp.) (1976). Los grupos étnicos y sus fronteras. La organización social de las diferencias culturales. México D. F.: FCE.

2. Bartolomé, M. (agosto, 2006). Los laberintos de la identidad: procesos identitarios en las poblaciones indígenas. Avá, (9), 28-47.

3. Canevacci, M. (2001). Antropologia da comunicação visual. Rio de Janeiro: DP\&A.

4. Cardoso de Oliveira, R. (1976). Um conceito antropológico de identidade. En R. Cardoso de Oliveira, Identidade, etnia e estrutura social (pp. 33-52). São Paulo: Livraria Pioneira Editora.

5. Coelho, R. F. (2007). Iniciação: um olhar videográfico sobre mito e ritual xavante (Dissertação mestrado, Universidade Estadual de Campinas, Campinas, Brasil). 


\section{DISERTACIONES}

ESTUDIOS

Comunicación indigena en América Latina

ISSN: 1856-9536

Doi: http://dx.doi.org/10.12804/revistas.urosario.edu.co/disertaciones/a.5708

Volumen 11, Número 2 / Julio-diciembre 2018

Versión PDF para imprimir desde

http://revistas.urosario.edu.co/index.php/disertaciones

6. Ewart, E. (2013). Space and society in central Brazil: a Panará ethnography. London: Bloomsbury (LSE Monographs on Social Anthropology).

7. Falleiros, G. L. J. (2012). Notas de mito-história política a'uwẽ-xavante. 28a Reunião Brasileira de Antropologia, PUc-sp, São Paulo.

8. Fernandes, E. R. (2010). Do Tsihuri ao Waradzu: o que as ideologias xavante de concepção, substância e formação da pessoa nos dizem sobre o estatuto ontológico do outro? Horizontes Antropológicos, 16(34), 453-477.

9. Franco Coelho, R. (2016). La apropiación cultural, social y política de los medios de comunicación en comunidades indígenas: el proyecto Aldea Digital en el pueblo xavante (Brasil central) (Tesis doctoral, Universidad Autónoma de Barcelona, Barcelona, España).

10. Geertz, C. (1997). Do ponto de vista dos nativos: a natureza do entendimento antropológico. En C. Geertz, O saber local: novos ensaios em antropologia interpretativa. Petrópolis: Vozes.

11. Giaccaria, B., \& Heide, A. (1984). Xavante: povo autêntico; pesquisa histórico-etnográfica. São Paulo: Editorial Salesiana Dom Bosco.

12. Graham, L. R. (1986). Three modes of Shavante vocal expression: wailing, collective singing, and political oratory. En J. Sherzer \& G. Urban, Native South American discourse (pp. 83-118). Berlín: De Gruyter.

13. Graham, L. R. (1993). A public sphere in Amazonia? The depersonalized collaborative construction of discourse in xavante. American Ethnologist, 20(4), 717-741.

14. Lévi-Strauss, C. (2008). As organizações dualistas existem? En C. Lévi-Strauss, Antropologia estrutural. São Paulo: Cosac Naify.

15. Lopes da Silva, A. (1986). Nomes e amigos: da prática xavante a uma reflexão sobre os jê. São Paulo: FFLCH-USP.

16. Maybury-Lewis, D. (1984). A sociedade xavante. Río de Janeiro: Francisco Alves.

17. Medeiros, S. L. R. (1991). O dono dos sonhos. São Paulo: Razão Social.

18. Müller, R. A. P. (1976). A pintura do corpo e os ornamentos xavante: arte visual e comunicação social (Dissertação mestrado, Universidade Estadual de Campinas, Instituto de Filosofia e Ciências Humanas, Campinas, Brasil).

19. Müller, R. A. P. (2007). Mensagens visuais na ornamentação corporal xavante. En L. Vidal (Org.), Grafismo indígena: estudos de antropologia estética. São Paulo: Studio Nobel-FAPESP.

20. Nimuendajú, C. (1942). The Serente. Los Ángeles: Frederick Webb Hodge Anniversary Publication Fund.

21. Nimuendajú, C. (1946). The Eastern Timbira. Berkeley-Los Ángeles: University of California Press.

22. Sereburã, Hipru, Rupawê, Serezabdi, \& Sereñimirãmi (1998). Wamrêmé za'ra nossa palavra: mito e história do povo xavante. São Paulo: Senac.

23. Shaker, A. F. (2002). Romhõsi'wai hawi rowa'õno re ihoimana mono: a criação do mundo segundo os velhos narradores xavante (Tese doutorado, Universidade Estadual de Campinas, Instituto de Filosofia e Ciências Humanas, Campinas, Brasil).

24. Spaolonse, M. B. (2006). Uma tradição em performance: corporalidade, expressividade e intercontextualidade num rito de iniciação social entre os xavante de Sangradouro (Dissertação mestrado, Universidade Federal de Santa Catarina, Centro de Filosofia e Ciências Humanas, Florianópolis, Brasil). 
25. Welch, J. R. (2010). Hierarchy, symmetry, and the xavante spiritual life cycle. Horizontes Antropológicos, 16(34), 235-259.

26. Welch, J. R. (2014). O sistema xavante de grupos de idade espirituais: estrutura e prática na vida dos homens. En J. R. Welch \& C. E. Coimbra Jr. (Eds.), Antropologia e história xavante em perspectiva. Río de Janeiro: Museu do Índio-Funai. 